Available online at https://jurnal.stmikroyal.ac.id/index.php/jurdimas

\title{
PELATIHAN PENGEMBANGAN KOMUNIKASI BAHASA INGGRIS BAGI IBU BHAYANGKARI DI POLSEK PORSEA
}

\author{
Cecep Maulana*1, Muthia Dewi ${ }^{2}$, Norenta Sitohang ${ }^{3}$ \\ Sistem Informasi, STMIK Royal Kisaran \\ Email: *cecep.maulana1977@gmail.com
}

\begin{abstract}
English conversations at Porsea Polsek especially for Ibu Bhayangkari to improve English communication that applies the use of Cooperative Learning method which makes it easy for participants to communicate. This is very influential of this method especially for learning activity and included English conversations about tourism objects, besides that, it is related about the dominant tourist destinations in Porsea and provide adequate knowledge to improve human resources in English. The training used is a form of training in the form of socialization using the Cooperative Learning method which aims to increase activity in developing oral communication skills.
\end{abstract}

Keywords: Developing English communication, Cooperative Learning method, Porsea Polsek

\begin{abstract}
Abstrak:kegiatan ini merupakan kegiatan pengabdian pada masyarakat berupa percakapan Bahasa Inggris di Polsek Porsea khusunya bagi ibu Bhayangkari untuk meningkatkan komunikasi bahasa inggris yang menerapkan penggunaan Cooperative Learning yang memudahkan bagi peserta dalam berkomunikasi. Hal ini sangat berpengaruh penerapan metode ini khusunya untuk kegiatan pembelajaran dan peningkatan percakapan bahasa inggris tentang objek wisata, hal ini didukung dengan adanya tujuan wisata yang dominan di porsea dan memberikan pengetahuan yang layak untuk meningkatkan sumber daya manusia dalam bahasa inggris. pelatihan yang digunakan adalah bentuk pelatihan dalam bentuk sosialisasi dengan menggunakan metode Cooperative Learning yang bertujuan meningkatkan aktivitas dalam mengembangkan keterampilan berkomunikasi secara lisan.
\end{abstract}

Kata kunci:Pengembangan Komunikasi Bahasa Inggris, Metode Cooperative Learning, Polsek Porsea

\section{PENDAHULUAN}

\footnotetext{
Porsea telah menjadi salah satu kecamatan di Kabupaten Tapanuli Utara ketika Kabupaten Toba Samosir masih belum dimekarkan. Pada tahun 1998, Kecamatan Porsea adalah salah satu kecamatan yang merintis pemekaran Kabupaten Toba Samosir.
}

Kecamatan Porsea terdiri dari 14 desa dan 3 kelurahan yang terbagi habis dalam 49 dusun. Kelurahan Patane III adalah ibukota dan pusat pemerintahan Kecamatan Porsea. Desa Raut Bosi merupakan desa dengan wilayah terluas yaitu $6,43 \mathrm{~km}^{2}$ atau $16,97 \%$ dari total luas Kecamatan Porsea, sementara Kelurahan Pasar. Porsea merupakan wilayah terkecil yaitu $0,08 \mathrm{~km}^{2}$ atau $0,21 \%$ dari total 
Available online at https://jurnal.stmikroyal.ac.id/index.php/jurdimas

luas Kecamatan Porsea.

Desa Amborgang merupakan desa yang paling jauh dari ibukota Kecamatan Porsea yaitu berjarak sekitar 11 kilometer. (https://id.wikipedia.org/wiki/

Porsea,_Toba_Samosir)

Pengembangan tempat-tempat wisata di Kecamatan Porsea harus pula dibarengi dengan peningkatan sumberdaya manusia, khususnya dalam bidang bahasa Inggris. Saat ini bahasa Inggris masih merupakan bahasa pengantar utama di dunia, sehingga masih dikatakan sebagai International Language. Tidak dapat dipungkiri pembelajaran bahasa Inggris yang diperoleh di SMP dan SMU belum memberikan jaminan bagi outputnya khususnya para pemuda dapat berbicara bahasa Inggris dengan baik. Oleh sebab itu untuk membantu untuk meningkatkan kemampuan bahasa Inggris para pemuda di Kecamatan Porsea, maka dilaksankan PKM (Pengabdian Kepada Masyrakat).

Kemampuan berbahasa Inggris yang dimaksud adalah pelatihan pengem-bangan komunikasi bahasa Inggris dalam bentuk percakapan sehari-hari bagi ibu Bayangkari di Porsea. Pelaksanaan kegiatan ialah dalam bentuk kursus. Hal ini dimaksudkan agar setelah selesai mengikuti kursus ini, pengetahuan yang diperoleh bisa segera diterapkan dalam kehidupan nyata yang ditemui di lapangan

Pengabdian kepada masyarakat adalah salah satu kewajiban dosen untuk berkontribusi untuk negeri. Penelitian dan Pengabdian Kepada Masyrakat merupakan elemen dari Tri Dharma Perguruan Tinggi. Kedua elemen tersebut menjadi aksi dari keterlibatan perguruan tinggi dalam pembangunan dan menghilangkan isolasi dunia akademik terhadap persoalan masyarakat.

Selain itu, masyarakat juga akan mendapatkan bekal untuk menyelesaikan permasalahan dan menjawab tantangan dalam kehidupannya. Masyarakat juga nantinya akan memberikan pembelajaran bagi perguruan tinggi tentang realitas kehidupan.

Tujuan dari Petunjuk Teknis Pengabdian kepada Masyarakat oleh Dosen adalah: 1). Membantu para dosen (individu dan kelompok) yang concern dalam pengabdian masyarakat untuk mengelaborasi suatu kawasan khusus dengan model pemecahan masalah dan pemberdayaan khas; 2). Menghasilkan Kegiatan Pelaksanaan Pengembangan yang terintegrasi dengan visi dan misi lembaga Perguruan Tinggi; 3. Menjadi panduan pengabdian kepada masyarakat oleh dosen.

Dengan demikian, PKM yang dilakukan untuk meningkatkan kemampuan berbicara bahasa Inggris dalam percakapan sehari-hari bagi ibu Bayangkari di POLSEK Porsea sungguh-sungguh merupakan kegiatan yang bersinergi secara positif dan bermanfaat bagi pemerintah daerah dan secara khusus bagi ibu Bayangkari di Porsea.

\section{METODE}

Kegiatan PKM di POLSEK Porsea bagi Ibu Bayangkari untuk meningkatkan kemampuan berbicara bahasa Inggris dalam percakapan sehari-hari dengan memperkenalkan penggunaan metode Cooperative Language Learning.

Cooperative Language Learning is a method that allows all students to work together, each student experiencing the role of teacher and of learner, and each student modeling recognition of and respect for many different skills and learning styles.(Cohen,Brody, dan Shevin, 2004:3)

Dengan kata lain Cooperative Language Learning adalah metode yang digunakan dalam pengajaran bahasa Inggris yang dilaksankan dengan cara bekerjasama antara peserta didik dalam proses belajar dan di dalam metode tersebut peserta yang merupakan ibu bayangkari di Polsek Porsea.

Menurut Kagan ada tujuh kunci

kesuksesaan dalam pelaksanaan metode Cooperative language learning (Kagan, 2009:5.2) adalah sebagai berikut:

\section{The Seven Keys}

Structures

How to use cooperative learning instructional strategies

Teams 
Jurdimas (Jurnal Pengabdian Kepada Masyarakat) Royal

Vol. 3 No. 1, Januari 2020, hlm. 17-22

DOI: https://doi.org/10.33330/jurdimas.v3i1.394

ISSN 2622-3813 (Online)

Available online at https://jurnal.stmikroyal.ac.id/index.php/jurdimas

How and when to form and re-form the various types of teams

3. Management

How to manage the cooperative classroom

4. Class building

How to create, caring, community of learners

5. Team building

How to develop powerful learning teams

6. Social Skills How to develop students' ability to cooperate

7. Basic Principles (PIES)

How to use the proven principles of cooperative learning.

Dari penjelasan pelaksanaan metode Cooperative language learning diatas, agar kegaitan ini terlaksana dengan lancar. Tujuan kegiatan pengabdian kepada masyarakat ini adalah:

Mempersiapkan materi yang akan diberikan, baik modul, slide presentasi, dan alat peraga lainnya.

Memastikan tempat dan fasilitas pendukung seperti infocus, projector, dan lain-lain sudah standby pada saat kegiatan akan dilangsungkan.

Sebelum kegiatan dilakukan peserta yang mengikuti kegiatan ini mendengarkan dengan seksama bagi Ibu bayangkari dan berusaha untuk memperaktekan secara bersama-sam melalui tampilan komputer atau laptop.

Menjelaskan teori tentang materi dengan : Introduction dan Daily Conversation kemudian dengan Praktek langsung/oral comunication

Diskusi dan tanya jawab dengan melakukan metode Cooperative language learning dengan Timed Pair Share "In pairs, students share with a partner for a predetermined time while the partner listens. Then partners switch roles" (Kagan, 2009: 6.38) Peserta didik dibuat berpasangan kemudian berdiskusi secara bergantian mengneai pertanyaan atau topic diskusi yang diberikan oleh pengajar.
Pembelajaran yang memiliki fungsi untuk meningkatkat kepribadian diri yang dapat bekerja sama dengan yang lain serta dapat juga meningkatkan kemampuan pengetahun sesuai materi yang ditargetkan dalam proses pembelajaran .

\section{PEMBAHASAN}

Pelatihan pengembangan komunikasi bahasa inggris dalam kegiatan pengabdian masyarakat dengan metode Communicative Language Teaching yaitu metode dengan saling berdiskusi dalam proses berbagi ilmu dan pengetahuan.

Seperti teori yang dinyatakan oleh Hymes di dalam (Richards and Rodgers, 2003:159) "language teaching is developed by communicative language teaching", yang artinya proses kegiatan belajar dilakukan secara komunikatif antara pemberi bahan belajar dan yang menerimanya

Dalam kegiatan ini POLSEK Porsea menyediakan tempat selama kegiatan dilangsungkan dan fasilitas-fasilas penunjang yang mereka punya untuk mendukung kegiatan ini berjalan dengan baik dan lancar.

Setelah kegiatan pengabdian kepada masyarakat ini dilakukan, maka langkah selanjutnya adalah Tim pengabdian kepada masyarakat melakukan monitoring selama 3 sampai 4 kali bagi Ibu Bayangkari untuk meningkatkan kemampuan berbicara bahasa Inggris dalam percakapan sehari-hari, Jika belum memahami materi secara sederhana, maka Tim akan menjelaskan kembali secara berulang-ulang sampai mereka memahami materi tersebut. Tinjauan ini dilakukan setiap satu kali dalam seminggu pasca kegiatan. berikut ini ada contoh materi dari pembahasan untuk menyatakan ungkapanungkapan perkenalan diri dalam bahasa inggris.

\section{Introduction:}

My name is Kartika (Nama saya Kartika)

My full name is Kartika Kirana (Nama lengkap saya Kartika Kirana) 
Available online at https://jurnal.stmikroyal.ac.id/index.php/jurdimas

My nick name is Kartika (Nama panggilan saya adalah Kartika)

Hi, I am Kartika (Hai, saya Kartika)

Hello, my name is Kartika (Halo, nama saya Kartika)

Good morning. My name is Kartika (Selamat pagi. Nama saya Kartika)

May I introduce myself? My name is Kartika (Bolehkah saya memperkenalkan diri? Nama saya Kartika)

Let me introduce myself. My name isKartika. (Ijinkan saya memperkenalkan diri. Nama saya Kartika)

First of all, I would like to introduce myself. My name is Kartika (Sebelumnya, saya ingin memperkenalkan diri dulu. Nama saya Kartika)

How do you do? My name is Kartika (How do you do?. Nama saya Kartika)

\section{Responses}

Hi, I'm Okki. Glad to meet you. (Hai, saya Okki. Senang bertemu dengan anda)

Hello, My name is Okki Pleased to meet you (Halo, nama saya Okki. Senang bertemu dengan anda)

Good morning. I am Okki How do you do?. (Selamat pagi. Nama saya Okki. How do you do?)

How do you do? My name is Okki. Nice to meet you (How do you do?. Nama saya Okki. Senang bertemu dengan anda)

\section{Introducing Others}

Do you know Kartika? (Apakah anda tahu Kartika?)

Have you met Kartika? (Pernahkah anda bertemu Kartika?)

This is a friend of mine,Okki. (Ini teman saya, Okki)

Ika, this is Okki, my friend. (Ika, ini Okki, teman saya)

May I introduce my friend, Mrs. Suryani? (Bolehkan saya memperkenalkan teman saya, Ibu Suryani?)

Please allow me to introduce our new Administration Manager. (Ijinkan saya untuk memperkenalkan manajer administrasi kita yang baru)

Let me introduce you to Mrs. Lina our new
Marketing Manager. Mrs. Lina. this is Mr. Lutfi from Java Plantation Company. (Ijinkan saya untuk memperke-nalkan anda kepada Ibu Lina, Manajer Marketing baru kita. Ibu Lina, Ini adalah Bapak Lutfi dari perusahaan Java Plantation).

\section{Responses}

No, I don't think so. (Sepertinya tidak)

No, I haven't. (Tidak, aku belum pernah)

$\mathrm{Hi}$, glad to meet you. I am Okki. (Hai, senang bertemu dengan anda. Saya Okki)

Hello, Okki. Pleased to meet you. (Halo Okki. Senang bertemu denganmu)

I am glad to know you (Saya senang bisa mengenal anda)

It is nice to see you. (Senang bisa melihat anda)

How do you do? (Ungkapan saat baru bertemu pertama kalinya)

How do you do? It is very nice to meet you. (How do you do? senang sekali bisa bertemu dengan anda)

\section{Daily Conversation}

Berdasarkan hasil pelaksanaan pelatihan pengembangan komunikasi bahasa Inggris oleh Dosen STMIK Royal Kisaran di Polsek Porsea, para ibu Bayangkari sudah memiliki pengetahuan dasar bahasa Inggris. Hal ini terwujud oleh karena adanya sosialisasi dan penyuluhanserta pembinaan bahasa Inggris secara intensif oleh dosen di lokasi tersebut.

Adapun tindak lanjut yang dapat dilakukan setelah pemberian dasar komunikasi bahasa Inggris kepada ibu Bayangkari, perlu adanya keberlanjutan program ini dengan kedepanya, mengingat dasar pemanfaatan bahasa yang sudah ada harus dapat dipraktekan secara kontinu. Selain itu, perlu ada dukungan pemerintah untuk membentuk pendidikan berupa lombaga kursus bahasa Inggris untuk mendukung pengetahuan dasar bahasa Inggris mereka yang sudah ada. Disini dapat diterapkan pelatihan pengembangan bahasa inggris dengan tema materi tentang objek wisata daerah yang sesuai dengan lingkungan atau tempat tinggal 
Available online at https://jurnal.stmikroyal.ac.id/index.php/jurdimas

mereka sebagai pengembangan komunikasi bahasa inggris khusussnya bagi ibu bhyangkari di Polsek Porsea.

Adapun materi bahan untuk capaian keberhasilan dalam komunikasi ini maka perlu memberikan informasi yang tepat dan akurat sehingga pelatihan ini berjalan dengan baik dan lancar .

penerapan metode cooperative learning dan percakapan yang harus di praktekan secara langsung. Hal ini dapat di ikuti bagi peserta khususnya /ibu bhyangkari dengan demikian, peserta melakukan oral communucation bersama dengan tpeserta lain hal ini dapat mempraktekan daily conversation dibawah ini:

\section{Listen Carefully these daily conversation}

Andita : Hello, excuse me, I am Andita. Do you speak English?

Budi : Yes, I do. I'm Budi. What can do for you, Andita?

Andita : I am sorry for interrupt you. I am a tourist from Indonesia. I want to go around and I think I need a partner. Do you want to be my guide?

Budi : Yes, of course. I know this place very well. There's no problem if I accompany you while explaining many things of this beautiful place.

Andita : That's cool. Thank you so much. I need a guide only for a day, so how much should I pay?

Budi : You just have to spend one dollar)

Andita : Okay, no problem. Please give me your best, Budi.

Budi : Sure, I will do my best

Andita : Thanks.

2. Practice with your patner

Santi : Hello, good afternoon, Sir.

Mr. Robert : Hello, good afternoon

Santi : May I talk with u for a while, Sir?

Mr. Robert : Yes, of course.

Santi : My name is Santi. What is your name,

Sir?

Mr. Robert : Hi Santi, my name is Robert.

Santi : Where are you from Mr. Robert?

Mr.Robert : Iam from New York, America.

Santi : Wow, so far away from here. How long have you been here Mr. Robert?
Mr. Robert : I have been here for three days. This is my second time in Porsea.

Santi : Is this your first time to visit here Mr. Robert?

Mr. Robert : Yeah, this is my first time to visit this place. I really want to come here.

Santi : So, what do you think about this place Mr. Robert?

Mr. Robert: I think this place is very interesting.

Santi : Yes, It is so very interesting

Mr. Robert : Yes, thanks for your additional information about this place.

Santi : Nice to meet you Mr. Robert.

Mr. Robert : Nice to meet you too Santi.

\section{SIMPULAN}

Kegiatan pengabdian kepada masyarakat yang dilakukan oleh Tim kegiatan (dosen STMIK Royal Kisaran) tepat pada sasaran. Materi kegiatan yang diberikan kepada peserta dapat digunakan dan dimanfaatkan untuk mengembangkan komunikasi bahasa inggris khususnya bagi ibu bhayangkari di Polsek porsea

\section{UCAPAN TERIMA KASIH}

Kegiatan pengabdian kepada masyarakat ini tidak terlepas dari kerjasama dan bantuan materi, tenaga, dan fikiran dari berbagai pihak. Untuk itu, Tim pengabdian kepada masyarakat mengaturkan ucapan terima kasih kepada semua pihak yang terlibat dalam kegiatan ini.

\section{DAFTAR PUSTAKA}

Cohen, Elizabeth G., Caleste M. Brody, and Mara Sapon Shevin. Teaching Cooperative Learning The Challenge for Teacher Education . Albany: State University of New York Press

https://id.wikipedia.org/wiki/Porsea,_Toba_S amosir 
Jurdimas (Jurnal Pengabdian Kepada Masyarakat) Royal

Vol. 3 No. 1, Januari 2020, hlm. 17-22

ISSN 2614-7912 (Print)

DOI: https://doi.org/10.33330/jurdimas.v3i1.394

ISSN 2622-3813 (Online)

Available online at https://jurnal.stmikroyal.ac.id/index.php/jurdimas

Kagan, Dr. Spencer and Miguel Kagan.(2009). Kagan Cooperative Learning. San Clamente: Kagan Publishing

Richards Jack C. and Theodore S. Rodgers. (2003). Approaches and Methods in Language Teaching second Edition . USA: Cambridge University Press 